\title{
Zoneamento Ambiental de Bacia Hidrográfica Dcupada por Assentamento Rural: Estuda de Caso do Córrego Indaiá- MS
}

\section{Environmental Zoning of Watershed Decupied by Rural Settlement: Case Study of the Indaiá Stream}

\author{
Leandro Félix da Siva * \\ Elias Rodrigues da Cunha** \\ Vitor Matheus Bacani ***
}

\begin{abstract}
Resumo:
A instalação de um complexo de assentamentos rurais na bacia hidrográfica do córrego Indaiá tem promovido alterações na dinâmica de uso da terra e cobertura vegetal. Neste sentido o zoneamento ambiental apresenta-se como uma boa alternativa para o manejo adequado dos recursos naturais. O objetivo deste trabalho foi elaborar uma proposta de zoneamento ambiental para a bacia hidrográfica do córrego Indaiá, localizada no sudeste do município de Aquidauana no estado do MS. O zoneamento ambiental foi elaborado através da combinação dos dados de fragilidade ambiental, uso da terra e cobertura vegetal e o código florestal brasileiro, a partir de análise espacial utilizando geotecnologias. Os resultados obtidos apresentaram-se bastante satisfatório e permitiram a definição de cinco zonas ambientais: zona de desenvolvimento agropastoril de alta restrição (36,56\%), zona de desenvolvimento agropastoril de média restrição $(21,30 \%)$, zona de proteção especial $(28,56 \%)$, zona de proteção máxima $(6,82 \%)$ e a zona estratégica de recuperação $(6,76 \%)$. A proposta de zoneamento ambiental indicou eficientemente áreas de preservação dos recursos naturais e de atividades econômicas que podem ser exercidas na bacia hidrográfica do córrego Indaiá.
\end{abstract}

\begin{abstract}
:
The installation of a rural settlement complex in the watershed stream Indaia has promoted changes in land-use and vegetation cover dynamics.In this sense, environmental zoning is a good alternative for the adequate management of natural resources. The aim of this work was to elaborate an environmental zoning proposal for the watershed stream Indaiá, located in the southeastern of the municipality of Aquidauana in the state MS. The environmental zoning was elaborated through combination of environmental fragility data, land-use and vegetation cover and brazilian forest code, starting spatial analysis using geotechnologies. The results obtained were very satisfactory and allowed the definition of five environmental zones: high restriction agropastoril development zone (36.56\%), agropastoril development zone $(21.30 \%)$, special protection zone $(28.56 \%)$, zone maximum protection $(6.82 \%)$ and the strategic recovery zone $(6.76 \%)$. The proposal of environmental zoning indicated efficiently areas for the preservation of natural resources and economic activities that can be carried out in the watershed stream Indaiá.
\end{abstract}

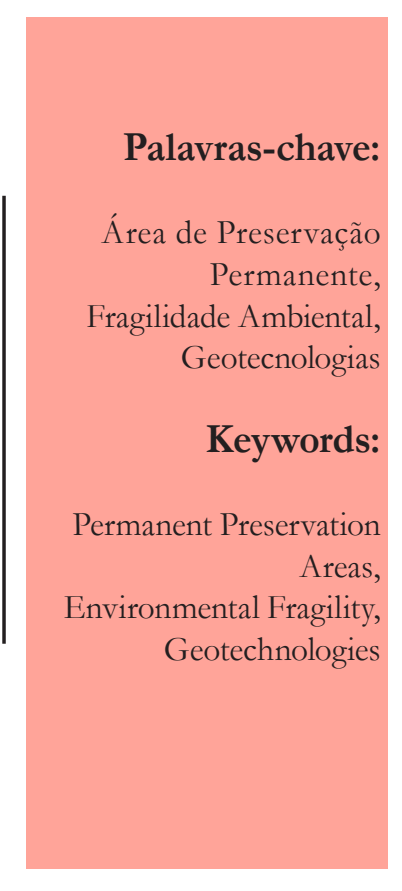

* Bacharel e MSc. em Geografia pela Universidade Federal do Mato Grosso do Sul (UFMS)

** Bacharel e MSc. em Geografia pela UFMS/CPTL. Técnico do laboratório de Geoprocessamento na UFMS/ CPAQ

*** Professor Adjunto da Universidade Federal de Mato Grosso do Sul, Campus de Três Lagoas 


\section{INTRODUÇÃO}

$\mathrm{O}$ zoneamento constitui um instrumento de ordenamento territorial, usado como recurso para se atingir melhores resultados no manejo de unidades de conservação e/ou bacias hidrográficas, pois estabelece usos diferenciados para cada zona, segundo seus objetivos. A Lei 9985/2000 define zoneamento como a criação de setores ou zonas em uma unidade de conservação com objetivos de manejo e normas específicas, com o propósito de proporcionar os meios e as condições para que todos os objetivos da unidade possam ser alcançados de forma harmônica e eficaz (BRASIL, 2000).

Alguns pontos julgados relevantes devem ser almejados na elaboração do zoneamento, conforme Becker e Egler (1996) seriam: a) Representar instrumento técnico de informações sobre o território, necessária para a sua ocupação racional e o uso sustentável dos recursos naturais; b) Prover uma informação integrada em uma base geográfica; c) Classificar o território de acordo com a sua capacidade de suporte ao uso e ocupação; d) Ser condicionante de planejamento e de gestão para o desenvolvimento em bases sustentáveis, colocando-se como instrumento corretivo e estimulador desse desenvolvimentos.

Dentro desta perspectiva, o planejamento econômico e ambiental de territórios municipais, estaduais, federais, bacias hidrográficas, ou qualquer outra unidade territorial, é necessário para que as intervenções humanas sejam planejadas com objetivos claros de ordenamento, tomando-se como premissas as potencialidades dos recursos naturais e humanos e as fragilidades dos ambientes (ROSS, 1994; 2012).

Desse modo, a busca por soluções se torna relevante e as adequações de metodologias e ferramentas para trabalhar o planejamento de unidades ambientais que apontem perspectivas mais coerentes e duradouras para a proteção, preservação e conservação das diversidades de paisagem e suas unidades sobre a superfície terrestre são cada vez mais desenvolvidas (GUERRA e MARÇAL, 2006).

Atualmente, o avanço tecnológico tem potencializado o uso de ferramentas como o sensoriamento remoto e o geoprocessamento, que permitiram o desenvolvimento de novas propostas metodológicas para avaliação de situações ambientais, além da possibilidade de cruzar informações de diversos tipos de variáveis a partir de análises espaciais. Sendo assim, é possível a separação dos ambientes naturais e dos ambientes alterados pelo homem, permitin- do propostas de hierarquização da situação desses ambientes que podem ser qualificados pelos níveis de fragilidade em que se encontram.

As unidades de fragilidade dos ambientes naturais devem ser resultantes de levantamentos básicos de geomorfologia, solos, riqueza da biodiversidade, uso e cobertura da terra e características climáticas. Esses elementos, trabalhados de forma integrada, possibilitam obter um diagnóstico das diferentes categorias hierárquicas da fragilidade dos ambientes naturais. Este tipo de abordagem resulta em cinco classes hierarquizadas de acordo com sua fragilidade e divididas em: muito fraca (1), fraca (2), média (3), forte (4) e muito forte (5) (ROSS, 2012; BACANI e LUCHIARI, 2014; BACANI et al. 2015).

Neste contexto, o objetivo deste trabalho foi de propor um novo zoneamento ambiental para a bacia hidrográfica do córrego Indaiá, em Aquidauana-MS, a partir de levantamentos de fragilidade ambiental, uso da terra e cobertura vegetal e a espacialização das restrições ambientais pautadas no Código Florestal Brasileiro (BRASIL, 2012) utilizando técnicas de geoprocessamento.

\section{METODOLOGIA}

\section{1 Área de estudo}

Localizada no estado de Mato Grosso do Sul, na região sudeste do município de Aquidauana, entre as latitudes $20^{\circ} 09^{\prime} 00^{\prime \prime}$ e $20^{\circ} 16^{\prime} 00^{\prime \prime}$ (S) e longitudes $55^{\circ} 29^{\prime}$ $30^{\prime \prime}$ e 55 39' 00" (W). Com uma área de aproximadamente $94,11 \mathrm{~km}^{2}$, (Figura 1).

A bacia hidrográfica do córrego Indaiá é um dos principais afluentes do rio Taboco, que adentra a planície pantaneira alimentado outros dois grandes rios da região: o Aquidauana e o Miranda, que são importantes componentes na dinâmica hídrica do Pantanal.

$\mathrm{Na}$ região encontra-se várias nascentes com água corrente que associados principalmente ao relevo e o predomínio de rochas sedimentares permitem o desenvolvimento de uma série de ambientes úmidos e diversificados como veredas, brejos e pequenos pântanos, que estão rodeados por fragmentos de florestas estacionais e Cerrado. Essa diversidade de ambientes apresenta fauna e flora silvestre bem diversificada e abundante o que demonstra a importância ambiental da região, tanto na questão hídrica como na questão biológica, mesmo sobre as constantes modificações que vem sendo exercidas a partir da ocupação humana e os modos no uso da terra 
que ali estão sendo exercidos pelo conjunto de assentamentos implantados na região da bacia.

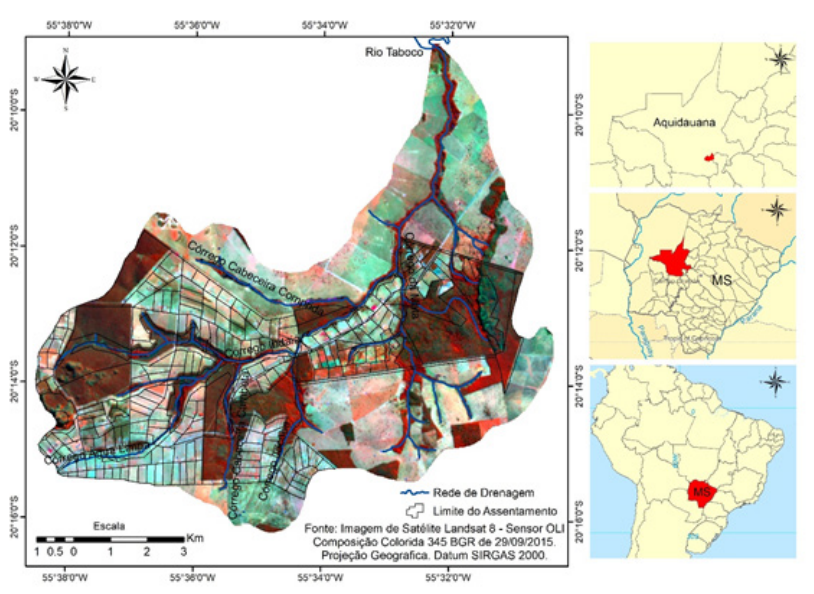

Figura 1 - Mapa de localização da bacia hidrográfica do córrego Indaiá e o conjunto de assentamentos

Fonte: Organização dos autores

Do ponto de vista geomorfológico, a bacia está inserida na macrounidade morfoestrutural: Bacia Sedimentar do Paraná, na Bacia Hidrográfica do Alto Rio Paraguai (BAP), subdivididas nas unidades morfoesculturais, Planalto Maracaju-Campo Grande e Depressão do Paraguai (BRASIL, 1982). As formas de relevo dominantes são colinas convexas, além da presença de planícies fluviais, morros e morrotes (CUNHA et al., 2013). O embasamento geológico é composto pelas Formações Furnas (Grupo Paraná), Aquidauana e aluviões fluviais (BRASIL, 1982).

Segundo Cunha et al., (2013) os solos predominantes na área investigada são: Gleissolos Tiomórficos de textura arenosa, localizados em toda a planície fluvial; Neossolos Quartzarênicos de textura arenosa, que predominam em mais da metade da área da bacia, faixa que vai desde algumas de suas nascentes (na margem esquerda) até a proximidade de sua foz com rio Taboco; Latossolos Vermelhos Álicos de textura franco-arenosa, encontrados ao longo de alguns dos seus tributários (na margem direita), ambos limitados com a planície fluvial; e Neossolos Litólicos de textura indiscriminada, encontrados nos morros e morrotes.

A bacia está inserida no domínio dos Cerrados, sendo que a vegetação que originalmente predomina na área é a Savana Arbórea Densa (Cerradão). Atualmente, destaca-se a presença de atividades agropecuárias e pastagens (BRASIL, 1982; SILVA et al., 2011).

O clima de Aquidauana/MS apresenta períodos sazonais definidos pelo inverno seco e verão chuvo- so, classificado como Aw de Köppen (tropical chuvoso). O total de chuvas anual se aproxima dos $1.400 \mathrm{~mm}$ (SANT'ANNA NETO, 1989). Amplitude térmica da região varia bastante, a média térmica é alta nos meses de verão com temperaturas superiores a $40^{\circ} \mathrm{C}$, e nos meses de inverno as temperaturas podem ser inferiores a $5^{\circ} \mathrm{C}$ (PINTO, 1998).

O processo de ocupação desta região, está ligado historicamente com a pecuária extensiva que tem sido uma das principais atividades na área de estudo, porém, o uso da terra no córrego Indaiá tem passado por uma expressiva transformação em função da instalação do primeiro complexo de assentamento rural do município de Aquidauana/MS. Em 15 de dezembro de 2009, o INCRA (Instituto Nacional de Colonização e Reforma Agrária) realizou o lançamento simultâneo dos quatro primeiros projetos de reforma agrária em Aquidauana/ MS. Ao todo, são 252 famílias beneficiadas pelo complexo de 6,4 mil hectares formado pelos assentamentos Indaiá I, II, III e IV (INCRA, 2013).

\subsection{Procedimentos Metodológicos}

Primariamente foi feita a delimitação da bacia hidrográfica do córrego Indaiá que se baseou na metodologia definida por Fitz (2008). A rede de drenagem foi extraída a partir de interpretação visual com auxilio de imagens de alta resolução espacial disponíveis no Google Earth, carta topográfica folha Aquidauana (SF. 21-X-A III) na escala de 1:100.000 elaborada pela Diretoria de Serviço Geográfico do Exército Brasileiro (DSG, 1960) e do Modelo Digital de Elevação (MDE) derivado dos dados Shuttle Radar Topography Mission (SRTM) disponível gratuitamente no sítio do INPE (www.dpi.inpe.br/Topodata) interpolados originalmente de 90 metros para 30 metros (VALERIANO, 2008).

A construção do zoneamento baseou-se em informações derivadas do mapa de fragilidade ambiental, uso da terra e cobertura vegetal e da legislação ambiental vigente pautada no Código Florestal Brasileiro (2012).

Para a criação do mapa de fragilidade ambiental foi necessário a criação do mapa de fragilidade potencial natural a erosão, e, posteriormente, a adição do mapa de uso da terra e cobertura vegetal como sugerido por Cunha et al., (2013), Pires et al., (2015) e Bacani et al. (2015).

A fragilidade potencial foi obtida pelo método de combinação entre mapas (álgebra de mapas), utilizando sobreposição ponderada no aplicativo ArcGIS 10. Este proce- 
dimento combinou dados de declividade, solos (CUNHA, 2013), intensidade pluviométrica (EMBRAPA, 2014) e a importância biológica (BRASIL, 2007).

Os dados de declividade foram desenvolvidos a partir do Modelo Digital de Terreno (MDT) oriundos dos dados do radar SRTM. O mapa de solos foi desenvolvido por Cunha (2013) no formato vetorial e na escala de 1:100.000 para região da bacia hidrográfica.

A intensidade pluviométrica (EMBRAPA, 2014) foi extraída a partir de médias anuais da Agência Nacional de Águas (ANA) de 03 estações pluviométricas: Cipolândia, Fazenda Lageado e Fazenda Taboco (disponível em http:/ / www.cpao.embrapa.br/clima/) e a representação da precipitação média anual pelo o método de interpolação denominado IDW (Inverse Distance Weighted).

A importância biológica derivou-se do levantamento feito pelo Ministério do Meio Ambiente para revisão das áreas prioritárias para a conservação, utilização sustentável e repartição de benefícios da biodiversidade brasileira em novembro de 2005 no formato Shapefile do banco de dados do MMA (disponível em http://mapas.mma.gov.br/i3geo/ datadownload.html). Em seguida o limite da bacia hidrográfica foi inserido como uma máscara sobre os dados de áreas prioritárias para a conservação e posteriormente recortado e editado as áreas de importância biológica.

$\mathrm{Na}$ sequência todos os dados foram submetidos a conversão de dados vetoriais para a estrutura matricial e reclassificados, atribuindo-lhe pesos baseados nas propostas de Ross (1994) e Crepani et al., 2001 para cada classe das variáveis utilizadas no software ArcGIS 10.

Para o mapa de uso da terra e cobertura vegetal optou-se pelas imagens do satélite LANDSAT-8, sensor OLI (Operational Land Imager) de 29 de setembro de 2015 órbita 225 , ponto 74 devido a disponibilidade gratuita e por conter imagens livres de nuvens, extraídas do banco de dados online do United States Geological Survey (USGS) disponível em http://earthexplorer.usgs.gov/.

Em seguida foi feito o recorte do limite da bacia sobre a imagem do satélite LANDSAT-8 para que a imagem passe pelo processo de classificação dos alvos. Para este processo optou-se pela classificação orientada a objeto, que está pautada em quatro etapas principais:

1) Pré-processamento: partiu da correção radiométrica da imagem e após termino desta correção, foi submetida ao um novo processo, o de correção atmosférica através da ferramenta FLAASH Atmospheric Correction. Por fim, foi feita a normalização das imagens corrigidas atmosfericamen- te, através da aplicação de uma função gaussiana, com a ferramenta Band Math no software ENVI 5.1.

2) Segmentação: A segmentação foi feita no software eCognition 8.0 e partiu da utilização da árvore de processo (Process Tree) no qual foram ajustados parâmetros de descrição como o algoritmo de segmentação a ser utilizado (Multiresolution Segmentation). Além do ajuste de valores dos elementos como escala (3), compacidade $(0,005)$ e forma $(0,003)$.

3) Classificação: A classificação foi executada através do classificador Nearest Neighbor (Vizinho Mais Próximo) disponível no software eCognition 8.0. Antes de executar a classificação, adicionou-se alguns parâmetros através da ferramenta de edição utilizados como critérios que auxiliam na potencialização do classificador na separação e identificação dos objetos na imagem. Os critérios adicionados foram as médias de refletância das bandas $(1,2,3,4,5,6$ e 7) da imagem do satélite LANDSAT 8/OLI; Geometria (área, índice de largura, largura e comprimento); Forma (assimetria, índice de borda, compacidade, índice de forma).

4) Exatidão da Classificação: Utilizou-se para avaliação dos resultados da classificação, a Matriz de Confusão (CONGALTON, 1991), na qual foi avaliada pelos coeficientes de Exatidão Global e Índice Kappa. Por fim os valores da Exatidão Global e Índice Kappa foram comparados aos limiares estabelecidos por Landis e Koch (1977).

$\mathrm{Na}$ sequência, o mapa de uso da terra e cobertura vegetal também passou pela conversão dos dados vetoriais para a estrutura matricial seguindo o mesmo procedimento anterior.

E por último o mapa de fragilidade ambiental, que foi elaborado também pelo método de álgebra de mapas, a partir da combinação dos mapas de fragilidade potencial natural a erosão e o uso da terra e cobertura vegetal.

A espacialização das restrições ambientais foi elaborada com base no Código Florestal Brasileiro lei no 12.651 de 25 de maio de 2012. As áreas de APPs (Áreas de Preservação Permanente) foram delimitadas a partir de uma ferramenta de criação de buffer ou distância. Para os córregos com largura inferior a 10 metros foram criados buffers com largura de 30 metros para cada lado ao longo dos canais de drenagem, já para as áreas de nascentes, foram gerados raios de 50 metros, a partir do ponto de cada nascente. Os vetores das Áreas de Reserva Legal e as Áreas de Remanescentes Florestais foram extraídos da Planta Geral do Projeto de Assentamentos Indaiá (INCRA, 2009).

A criação do mapa de zoneamento ambiental ba- 
seou-se nas propostas metodológicas descritas por IBAMA (2001), Ross (2006), Bacani e Luchiari (2014) que estão fundamentadas na identificação de zonas a partir da análise da fragilidade ambiental ou emergente (que inclui a análise do uso atual da terra) e a espacialização das restrições ambientais pautadas no Código Florestal Brasileiro (2012).

A partir destas propostas metodológicas para zoneamento ambiental somadas ao trabalho de campo no qual foram coletados pontos de Sistema de Posicionamento Global (GPS- Global Positioning System), o registro feito através de fotos tiradas in loco no período do mês de setembro de 2014 e trabalho de gabinete, é que se propôs a definição de 5 (cinco) tipos de zonas ambientais para a bacia hidrográfica, conforme o sintetizado na Figura 2.

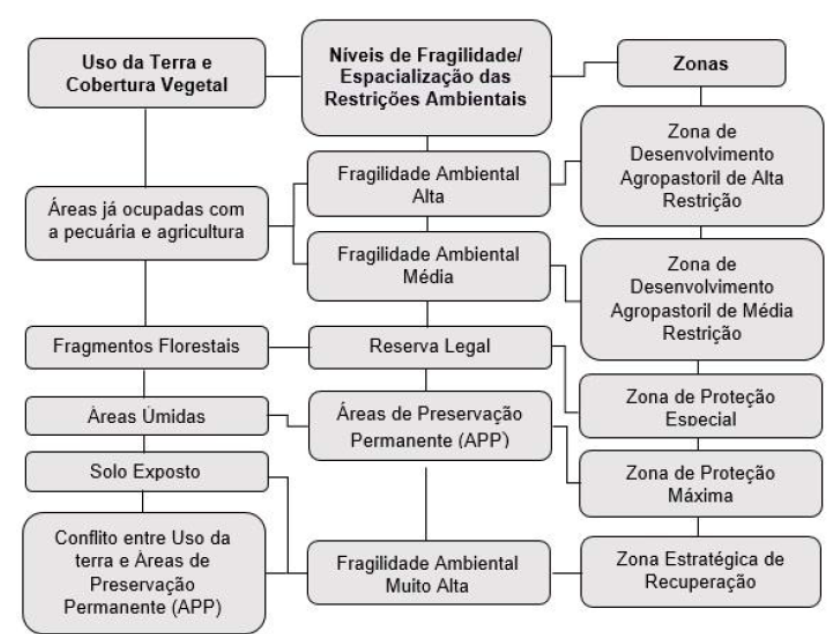

Figura 2 - Critérios utilizados na elaboração do zoneamento Fonte: Organização dos autores

\section{RESULTADO E DISCUSSÃO}

\subsection{Uso da terra e cobertura vegetal}

Primeiramente foram avaliados os parâmetros estatísticos do mapeamento de uso da terra e cobertura vegetal para a bacia hidrográfica que foi obtido através do Índice de concordância Kappa (0.7685) e Acurácia Global (0.8146) ambos qualificados como Muito Bom segundo o estipulado por Lands e Koch (1977).

O mapeamento da imagem de satélite 2015 possibilitou a identificação de 4 classes de uso da terra e cobertura vegetal: Área Úmida, Agropecuária, Solo Exposto e Fragmentos Florestais (Figura 3).

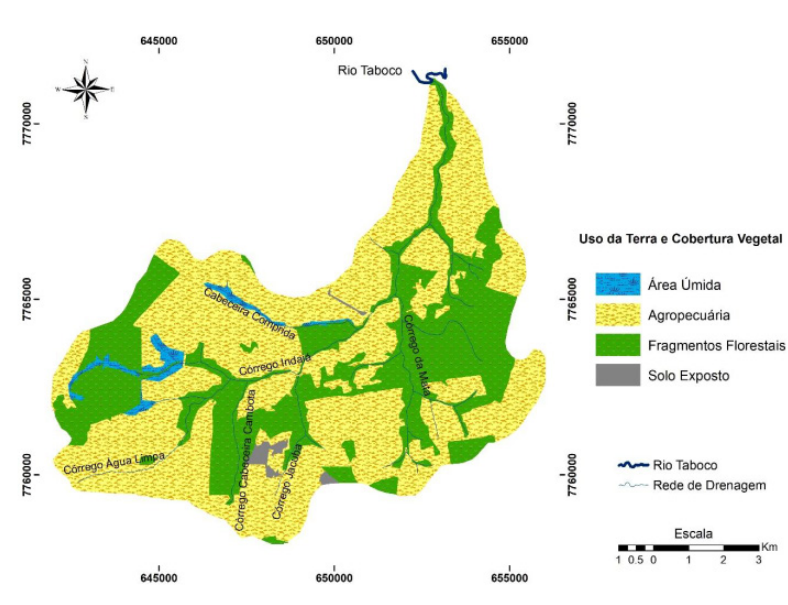

Figura 3 - Mapa de uso da terra e cobertura vegetal do ano de 2015 Fonte: Organização dos autores

Na sequência a Tabela 1 demonstra os valores de cada classe de uso da terra e cobertura vegetal em quilômetros quadrado $\left(\mathrm{Km}^{2}\right)$ e em porcentagem (\%).

Área úmida é uma classe composta por regiões brejosas nas planícies de inundação refletindo os efeitos das cheias e as veredas nas depressões alagáveis, composta por vegetação aquática, ervas arbustos e palmeiras adaptadas aos solos úmidos. Ocupa uma área de 1,77 $\mathrm{km}^{2}$, aproximadamente $1,88 \%$ da região da bacia.

As regiões de agropecuária são formadas pela ocupação das áreas por pastagens exóticas e de agricultura. As principais atividades desenvolvidas são a pecuária de corte com poucas cabeças de gado e agricultura com pequenas plantações de milho, mandioca, abacaxi e outras frutas, grãos e cereais, ambas atividades de subsistência. E é a maior classe mapeada e abrange $59,17 \mathrm{~km}^{2}(62,87 \%$ da bacia).

Tabela 1- Quantificação das áreas de uso da terra e cobertura vegetal

\begin{tabular}{lll}
\hline Classes de uso da terra e cobertura vegetal & Área $\left(\mathrm{Km}^{2}\right)$ & $(\%)$ \\
\hline Área Úmida & 1,77 & 1,88 \\
Agropecuária & 59,17 & 62,87 \\
Fragmentos Florestais & 32,43 & 34,46 \\
Solo Exposto & 0,74 & 0,79 \\
\hline Total & 94,11 & 100 \\
\hline
\end{tabular}

Fonte: Organização dos autores

Os fragmentos florestais ocupam $32,43 \mathrm{~km}^{2}$ $(34,46 \%)$ da região é formado por vegetação nativa que ainda estão preservadas. Esses fragmentos são compostos por Floresta Estacional Decidual e Semidecidual, Cerrado Sentido Restrito, Cerradão e Mata Ciliar.

O solo exposto indica áreas que não apresentam 
nenhum tipo de cobertura vegetal como renovação de pasto e das áreas de queimadas. Atualmente representam $0,74 \mathrm{~km}^{2}$ da região da bacia aproximadamente $0,79 \%$.

\subsection{Fragilidade ambiental}

A combinação da fragilidade potencial com o uso da terra e a cobertura vegetal resultou em quatro níveis de fragilidade ambiental: baixa, média, alta e muito alta (Figura 4).

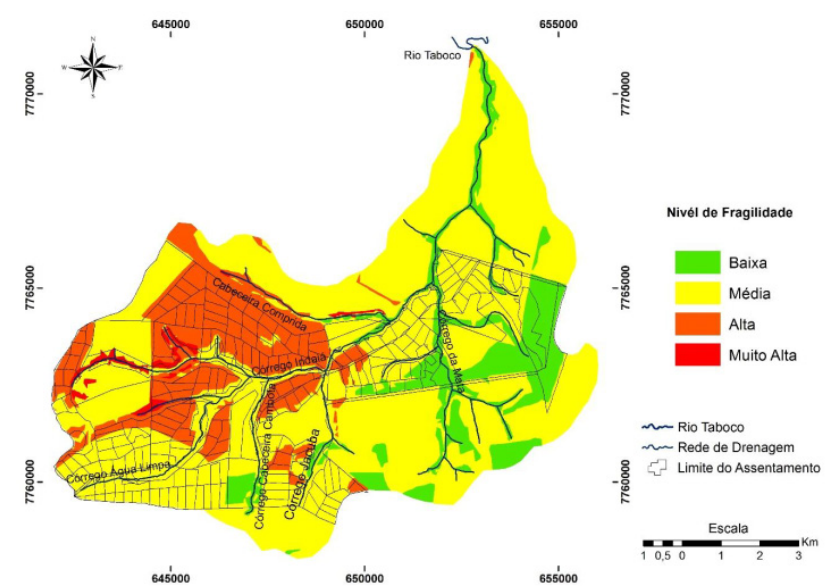

Figura 4 - Mapa de fragilidade ambiental Fonte: Organização dos autores

As áreas de baixa fragilidade ambiental ocupam $11,80 \mathrm{~km}^{2}$ (Tabela 2) situadas ao sul nas margens do córrego Cabeceira Cambota e Jacuba, a leste próximo ao córrego da Mata. O grau de fragilidade é resultado da baixa fragilidade potencial associada à proteção do solo pela presença da vegetação nativa (floresta estacional semidecidual) e fragmentos de mata ciliar, além de estarem situadas em áreas de declividades que variam de 0 a $6 \%$ conforme também constatado por Cunha e Bacani (2013).

A classe média fragilidade ambiental é a maior classe mapeada e ocupa $64,78 \mathrm{~km}^{2}(68,84 \%$ da área de estudo), localizando-se principalmente em áreas recobertas predominantemente por gramíneas exóticas (pastagem), onde se desenvolve relevo com formas onduladas e com inclinações de até $12 \%$.

Tabela 2 - Quantificação das áreas de fragilidade ambiental

\begin{tabular}{lll}
\hline Grau de Fragilidade Ambiental & Área $\left(\mathrm{km}^{2}\right)$ & $\%$ \\
\hline Baixa & 11,80 & 12,54 \\
Média & 64,78 & 68,84 \\
Alta & 16,37 & 17,39 \\
Muito Alta & 1,16 & 1,23 \\
\hline Total & 94,11 & 100 \\
\hline
\end{tabular}

Fonte: Organização dos autores
A classe alta fragilidade ambiental ocupa aproximadamente $16,37 \mathrm{~km}^{2}$, o equivalente a $17,39 \%$ da área de estudo, e está associada diretamente com as áreas de pastagem degradada. O solo predominante nessa área é o Neossolo Quartzarênico, trata-se de um solo arenoso com baixa capacidade de retenção de água e que está associado as declividades superiores a $20 \%$ de inclinação, em determinadas localidades com níveis avançados de processos de erosivos. Além desta área ser classificada como de importância biológica extremamente alta devido à grande concentração de nascentes de água e dos fragmentos de remanescentes florestais que contribuiu significativamente para a classificação das áreas de alta fragilidade.

Cunha et al. (2013) constataram que as nascentes do córrego Indaiá estão localizadas em áreas de alta fragilidade, fato que implica uma atenção maior para essas áreas de afloramento do lençol freático. Ao comparar os resultados de Cunha et al. (2013) com os desenvolvidos nesta pesquisa a partir de variáveis diferentes, pôde se observar que houve uma corroboração de destas informações principalmente com o avistado em campo.

Outro fator determinante constatado nesta pesquisa além das supracitadas é que grande parte da área de vegetação nativa destinada à preservação foram desmatadas ou queimadas intencionalmente no intuito de obtenção de carvão e na limpeza do terreno ocasionando a redução da cobertura vegetal nativa, ação que provoca a perda de proteção do solo e das nascentes.

As constantes queimadas ocasionadas por ação antrópica no intuito de obtenção de carvão ou na limpeza do terreno são muito comuns na região da bacia, apresentando-se como ato cultural para este tipo de necessidade. Neste sentido Ribeiro et al. (2012) mostram que as constantes queimadas em áreas de cerrados oriundas de ação humana afetam a sobrevivência e o crescimento da vegetação lenhosa. Em áreas de floresta estacional semidecidual a mortalidade de árvores pode alterar a composição e estrutura da vegetação, dependendo da intensidade, frequência e duração das queimadas, assim como constatado por Peixoto et al., (2012), formações vegetais essas que estão presentes na área da bacia.

As áreas de muito alta fragilidade ambiental caracterizam-se pela presença das áreas úmidas (brejos e veredas), solo exposto, alta declividade (acima de 30\%) e a importância biológica classificada como extremamente alta. Representam 1,16 km², o equivalente a 1,23\% da bacia hidrográfica. 


\subsection{Espacialização das restrições ambientais}

A rede de drenagem da bacia hidrográfica do córrego Indaiá é composta por 6 córregos principais: Água Limpa, Cabeceira Cambota, Cabeceira Comprida, Córrego da Mata, Indaiá e Jacuba. Todos apresentam cursos fluviais de largura inferior a 10 metros, o que resultou em faixas de APPs com 30 metros de largura em ambos os lados.

Já para as regiões de nascentes, foram identificados 24 pontos de nascentes o que resultou nas áreas de proteção permanente com raio de 50 metros para cada ponto. E por fim, as áreas de Reserva Legal e Remanescentes Florestais encontram-se ao longo da bacia em áreas de vegetação nativa que foram definidas pelo INCRA, quando se instalou o assentamento Indaiá (Figura 5).

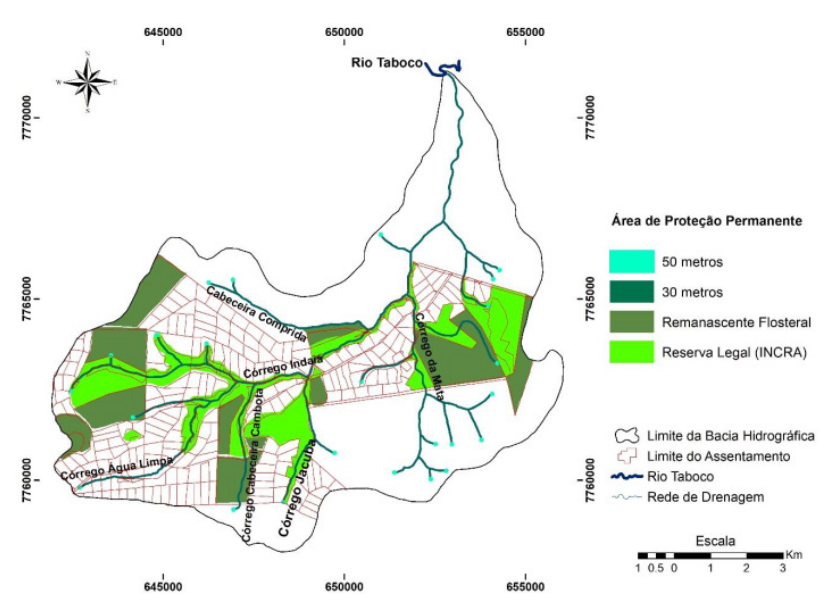

Figura 5 - Mapa da espacialização das restrições ambientais baseado no Código Florestal Brasileiro (BRASIL, 2012)

Fonte: Organização dos autores

A Tabela 3 apresenta a quantificação em quilômetros quadrados $\left(\mathrm{km}^{2}\right)$ e porcentagem (\%) das áreas destinadas à preservação permanente (APP).

Tabela 3- Quantificação das áreas de fragilidade ambiental.

\begin{tabular}{lll}
\hline Faixa de Proteção & Área $\left(\mathrm{Km}^{2}\right)$ & $\%$ \\
\hline Curso hídrico com largura menor que $10 \mathrm{~m}(30 \mathrm{~m})$ & 3,85 & 13,65 \\
Entorno das Nascentes $50 \mathrm{~m}$ & 0,18 & 0,64 \\
Remanescentes Florestais & 11,84 & 41,97 \\
Reserva Legal & 12,34 & 43,74 \\
Total & 28,21 & 100 \\
\hline
\end{tabular}

Fonte: Organização dos autores

Ao estudarem as áreas de conflito entre uso da terra e cobertura vegetal e a legislação ambiental, Cunha e Bacani (2013) identificaram que a introdução de pastagem exótica ao longo das margens do córrego Água Limpa facilitou a contaminação por sedimento e assoreamento do canal. Considerando os aspectos físicos-naturais (relevo, solos, geologia e pluviosidade) tornam a região naturalmente susceptíveis aos processos erosivos, que são intensificados ainda mais com as atividades humanas ali exercidas. $\mathrm{O}$ avanço da pastagem e a ocorrência de processos erosivos não se limitam apenas no córrego Água Limpa, e também se encontram presentes nas margens e nascentes do córrego Indaiá e seus afluentes (Cabeceira Comprida, córrego Jacuba e córrego da Mata).

Neste sentido, as áreas que deveriam ser ocupadas por formações vegetais nativas segundo o Código Florestal Brasileiro (BRASIL, 2012), não estão sendo preservadas em grande parte da bacia. As preservações da vegetação nativa destas áreas são de suma importância, uma vez que atuam como proteção dos corpos hídricos regulando os processos de troca entre os ecossistemas terrestres e aquáticos desenvolvendo condições propícias à infiltração (KAGEYAMA, 1986; LIMA, 1989), o que não vem acontecendo com os córregos e as nascentes da bacia conforme o constado.

A espacialização das APPs com o uso de geotecnologias e trabalho de campo permitiu verificar que as disposições definidas pelo novo Código Florestal Brasileiro (BRASIL, 2012), não estão sendo cumpridas, uma vez que as áreas restritas a preservação e conservação estão sendo modificadas em decorrência do manejo inadequado das atividades econômicas ali exercidas conforme o identificado por esta pesquisa, tais como:

- Desmatamentos das margens do córrego Indaiá e seus tributários;

- Represamentos e captação de água em diversos pontos do córrego Água Limpa;

- Desmatamento e queima da vegetação nativa das áreas de Reserva Legal e Remanescentes Florestais;

- Desmatamento da vegetação nativa no entorno das nascentes

\section{ZONEAMENTO AMBIENTAL}

O zoneamento ambiental (Figura 6) proposto apresentou cinco tipos de zonas diferentes, sendo duas de uso para atividades de produção: 1. Zona de Desen- 


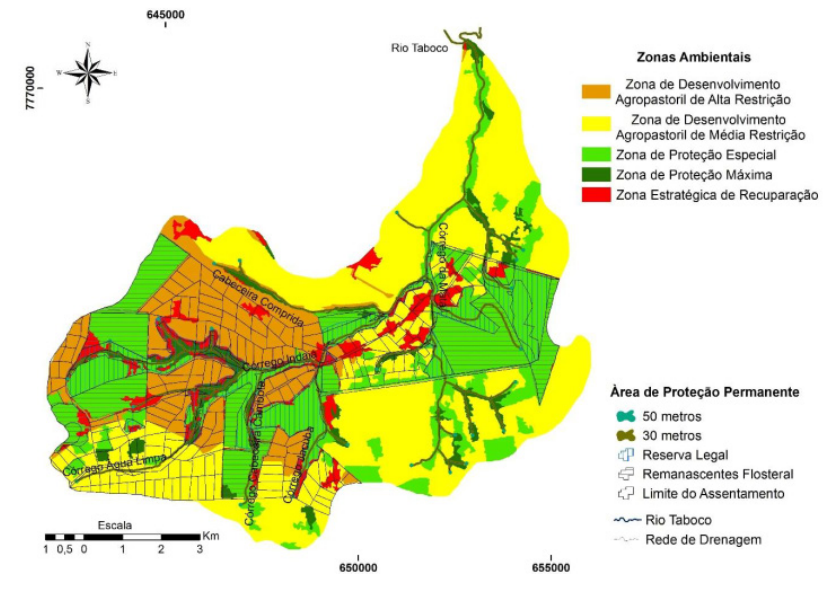

Figura 6 - Mapa do zoneamento ambiental da bacia hidrográfica do córrego Indaiá

Fonte: Organização dos autores

volvimento Agropastoril de Alta Restrição (ZDAAR), 2. Zona de Desenvolvimento Agropastoril de Média Restrição (ZDAMR); duas de Proteção da biodiversidade: 3. Zona de Proteção Máxima (ZPM), 4. Zona de Proteção Especial (ZPE); e uma zona voltada estrategicamente à recuperação da vegetação nativa e áreas degradadas: 5 . Zona Estratégica de Recuperação (ZER).

A Tabela 4 apresenta as zonas ambientais da bacia hidrográfica do córrego Indaiá quantificadas em quilômetros quadrados $\left(\mathrm{km}^{2}\right)$ e porcentagem (\%).

Tabela 4 - Quantificação das áreas de fragilidade ambiental

\begin{tabular}{lll}
\hline Zonas Ambientais & Área $\left(\mathrm{km}^{2}\right)$ & $\%$ \\
Zona de Desenvolvimento Agropastoril de Alta Restriçāo (ZDAAR) & 14,67 & 15,59 \\
Zona de Desenvolvimento Agropastoril de Média Restriçāo (ZDAMR) & 39,78 & 42,27 \\
Zona de Proteçāo Especial (ZPE) & 26,88 & 28,56 \\
Zona de Proteçāo Máxima (ZPM) & 6,42 & 6,82 \\
Zona Estratégica de Recuperaçāo (ZER) & 6,36 & 6,76 \\
\hline Total & 94,11 & 100 \\
\hline
\end{tabular}

Fonte: Organização dos autores

\subsection{Zona de desenvolvimento agropastoril de alta restrição}

Esta zona é indicada para produção agropecuária, e considera às atividades que já vem sendo desenvolvidas na região. A zona ocupa 15,59 $\mathrm{km}^{2} \mathrm{da}$ área da bacia, o que corresponde a $14,67 \%$.

A alta restrição é por se tratar de uma área de alta fragilidade ambiental e, portanto, mais suscetível à degradação devido às atividades que estão sendo desenvolvidas atualmente, como a pecuária sem acompanhamento e manejos adequados. E por se tratar de uma área de pre- dominantemente de solos arenosos, que segundo Fushimi et al., (2013) tendem a ser mais vulneráveis à erosão, principalmente em áreas de pastagens degradadas.

Desse modo, a ZDAAR requer um cuidado maior nos modos de uso para serem exploradas por atividades econômicas, o que requer um manejo adequado com orientação técnica, respeitando-se as práticas conservacionistas do solo, conforme recomendado por Oliveria et al., (2011) e Fushimi et al., (2013). Desse modo recomenda-se que as atividades ligadas à agricultura intensiva e a utilização de culturas de ciclo curto sejam evitadas devido ao alto impacto gerado sobre os recursos. A Figura 7 apresenta imagens que caracterizam a zona de desenvolvimento agropastoril de alta restrição (ZDAAR).

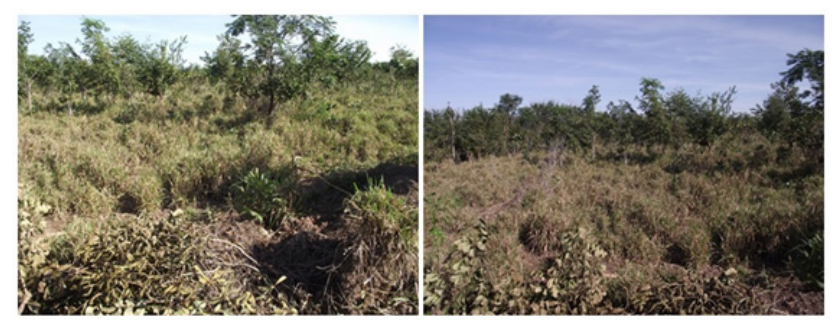

Figura 7 - Zona de desenvolvimento agropastoril de alta restrição (ZDAAR)

Fonte: Acervo particular dos autores (setembro de 2014)

\subsection{Zona de desenvolvimento agropastoril de média restrição}

A zona de desenvolvimento agropastoril de média restrição (Figura 8) possui uma área de aproximadamente $39,78 \mathrm{~km}^{2}$, ocupando $42,27 \%$ e tem por finalidade o desenvolvimento de atividades econômicas mais intensivas como a criação de gado de corte e leite; plantio de culturas de ciclo longo e curto (grãos) e cultivo de espécies frutíferas. Apresentou melhores condições de uso para o desenvolvimento de atividades um pouco mais intensas quando comparada a ZDAAR, por se tratar de uma área onde a fragilidade ambiental média predomina. A ZDAMR é formada por relevos ondulados que variam
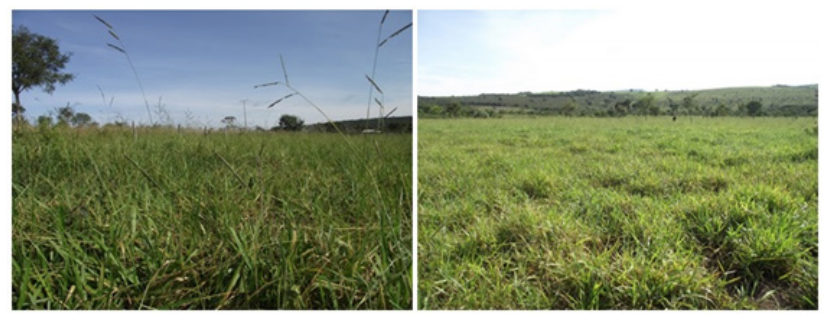

Figura 8- Zona de desenvolvimento agropastoril de média restrição (ZDAMR).

Fonte: Acervo particular dos autores (setembro de 2014). 
de 12 a 20\%, além das pastagens não estarem degradadas, o que oferece um estado mais favorável à exploração de atividades agropecuárias com acompanhamento técnico no manejo.

\subsection{Zona de proteção especial}

A zona de proteção especial (Figura 9) abrange $26,88 \mathrm{~km}^{2}$, e ocupa $28,56 \%$ da área. Ela tem a função de preservar as formações vegetais ainda existentes, que se destacam pela rica diversidade de fitofisionomias presentes na bacia (Floresta Estacional Decidual e Semidecidual, Cerrado Sentido Restrito e Cerradão) e que tem a capacidade de comportar fauna e flora típica desse tipo de ambiente (SILVA et al., 2011).
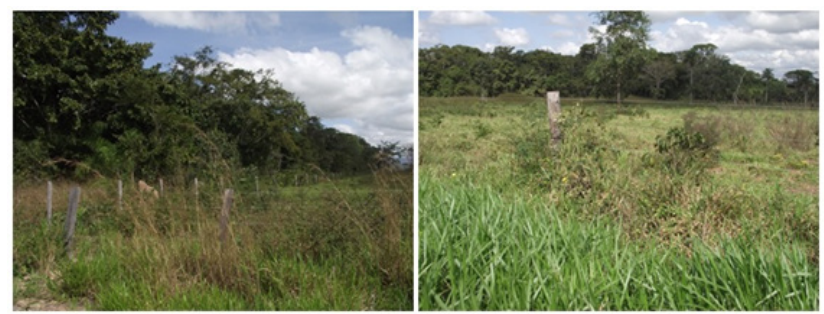

Figura 9 - Zona de proteção especial (ZPE)

Fonte: Acervo particular dos autores (setembro de 2014)

\subsection{Zona de proteção máxima}

A zona de proteção máxima (Figura 10) ocupa $6,42 \mathrm{~km}^{2}$, o equivalente $6,82 \%$ da área de estudo. Esta zona foi criada para assegurar a proteção das APPs que já são protegidas pelo Código Florestal Brasileiro (BRASIL, 2012). Nessas áreas encontram-se fitofisionomias como mata de galeria, mata ciliar, veredas e campos recobertos por gramíneas nativas. A preservação das áreas úmidas (ambientes brejosos) principalmente das veredas é de suma importância, uma vez que grande parte das nascentes de água que alimentam os córregos da bacia surgem sobre a proteção dessas formações vegetais nativas. Essas

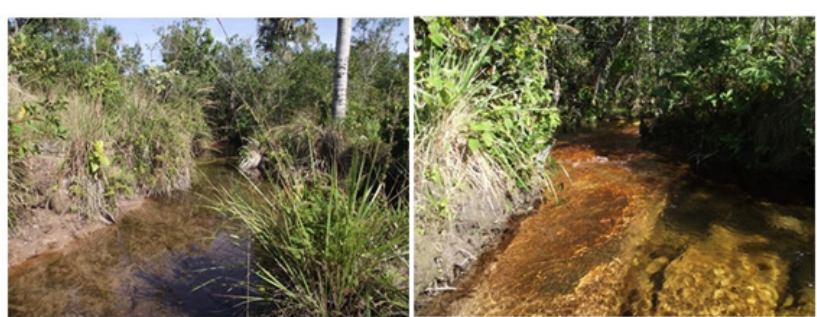

Figura 10- Zona de proteção máxima (ZPM).

Fonte: Acervo particular dos autores (setembro de 2014). áreas exercem um papel fundamental no sistema hidrológico e na manutenção da fauna do Cerrado, funcionando como local de pouso para várias espécies de aves migratórias, atuando também como refúgio, abrigo, fonte de alimento e local de reprodução para a fauna terrestre e aquática (BRANDÃO et al., 1991; CARVALHO, 1991).

\subsection{Zona Estratégica de Recuperação}

A zona de estratégica de recuperação (Figura 11) ocupa $6,36 \mathrm{~km}^{2}$, o equivalente a $6,76 \%$ da área. A finalidade desta zona é promover a recuperação de áreas que sofreram altos níveis de degradação ambiental, em decorrência dos processos erosivos, desmatamentos e queimadas não controladas. Tem por finalidade recompor áreas degradadas, devido o papel que essas áreas exercem na proteção dos mananciais, além da alta importância biológica na composição da biodiversidade da região. Este trabalho pode ser feito através de projetos de extensão, de ensino e pesquisa desenvolvidos através das universidades e outros institutos de pesquisas em parceria com a Agência de Desenvolvimento Agrário e Extensão Rural (AGRAER) e com a participação da comunidade local. A recuperação pode ser feita com espécies nativas cultivadas da região ou com a própria vegetação secundária que se reconstitui naturalmente.

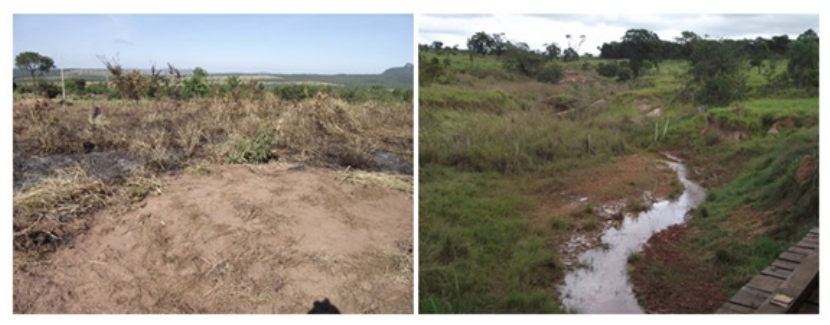

Figura 11- Zona de estratégica de recuperação (ZER)

Fonte: Acervo particular dos autores (setembro de 2014)

Trabalhos utilizando metodologias semelhantes na análise de fragilidade dos ambientes e no uso ocupação dos recursos naturais, para a criação de propostas de zoneamentos ambientais mostraram-se muito eficientes (LOPES et al., 2012; REMPEL et al., 2012; THOMAS, 2012; SILVA NETO, 2014) e corroboram com alguns dos resultados obtidos nesta pesquisa.

Este estudo por sua vez apresentou algumas vantagens quando comparado com os demais, principalmente pela utilização de variáveis como a importância biológica dos ambientes disponível pelo Ministério do Meio Ambiente (MMA), o que permitiu potencializar ainda 
mais as áreas de preservação, além da espacialização e a combinação com instrumentos normativos como o Código Florestal Brasileiro (2012) utilizando geotecnologias e a bacia hidrográfica como unidade de planejamento.

\section{CONCLUSÃO}

O resultado da proposta de zoneamento ambiental obtido nesta pesquisa através do processo metodológico que combinou variáveis como o mapa de fragilidade ambiental, uso da terra e cobertura vegetal e instrumentos normativos vigentes (Código Florestal Brasileiro) através do uso de geotecnologias indicou eficientemente áreas de preservação dos recursos naturais e de atividades que podem ser exercidas na bacia, e apontou que mais da metade da área pode ser utilizada para atividades econômicas como agricultura e pecuária de subsistência.

As zonas sugeridas para atividades econômicas levaram em consideração principalmente as atividades que já vem sendo desenvolvidas na bacia, além de recomendar outras que podem ser exercidas a partir da capacidade natural dos ambientes, com o acompanhamento e orientações técnicas no manejo adequado dessas atividades que infelizmente são ausentes para os assentados que acabam fazendo o uso inadequado dos recursos naturais aumentando os níveis de degradação.

Além disso, o estudo também delimitou as áreas a serem preservadas e recuperadas na bacia hidrográfica do córrego Indaiá ressaltando a importância da preservação dos ambientes naturais ali ainda existentes que exercem um papel fundamental na manutenção e no equilíbrio das áreas naturais principalmente na proteção dos mananciais.

Nesta perspectiva a proposta de zoneamento ambiental pode servir de ferramenta para o ordenamento físico territorial e auxiliar também no programa de gerenciamento de bacias hidrográficas em área de assentamentos rurais.

$\mathrm{O}$ uso de geotecnologias mostrou-se de suma importância para o desenvolvimento da proposta de zoneamento ambiental em bacia hidrográfica ocupada por assentamento rural. A quantidade de informações organizadas em um banco de dados geográficos permitiu uma visão geral das atividades exercidas e possibilita atualização e monitoramento de maneira eficiente das atividades econômicas desenvolvidas sobre os recursos naturais.

\section{REFERÊNCIAS}

ARCGIS/ARCINFO - Esri Inc. ArcGis Version 10. Environmental Systems Research Institute Inc. New York, 1 Cd Rom 2012.

BACANI, V. M. LUCHIARI, A. Geoprocessamento aplicado ao zoneamento ambiental da bacia do alto rio Coxim-MS. GEOUSP - Espaço e Tempo, São Paulo, v. 18, n. 1, p. 184-197, 2014.

BACANI, V. M. SAKAMOTO, A. Y. LUCHIARI, A. QUÉNOL, H. Sensoriamento remoto e SIG aplicados à avaliação da fragilidade ambiental de bacia hidrográfica. Mercator, Fortaleza, v. 14, n. 2, p. 119-135, mai./ago. 2015.

BRANDÃO, M.; CARVALHO, P. G.S. BARUGUI, F. M. Veredas uma abordagem integrada. DAPHNE - Revista do Herbário PAMG, Belo Horizonte, v,1, n.3, p.5-8,1991.

BRASIL, Ministério das Minas e Energias. Secretaria Geral. Projeto RADAMBRASIL: Geologia, Geomorfologia, Pedologia, Vegetação e Uso potencial da terra.,. Folha SE. 21. Campo Grande. Rio de Janeiro, 1982.

BRASIL. Áreas Prioritárias para Conservação, Uso Sustentável e Repartição de Benefícios da Biodiversidade Brasileira: Atualização - Portaria MMA n 9 , de 23 de janeiro de 2007/Ministério do Meio Ambiente, Secretaria de Biodiversidade e Florestas. - Brasília: MMA, 2007.

BRASIL. Sistema Nacional de Unidades de Conservação da Natureza - SNUC. Lei No 9.985, de18 de Julho de 2000. Brasilia, Diário Oficial da União, 2000.

BRASIL. Código Florestal Brasileiro. Lei 12.651, de 25 de maio de 2012. Brasília, Diário Oficial da União, 2012.

BRASIL. Lei $\mathrm{n}^{\circ}$ 12.651, de 25 de maio de 2012. Dispõe sobre a proteção da vegetação nativa. Diário Oficial da União, Brasília, DF, 28 mai. 2012.

BECKER, B. K.; EGLER, C. A. G. Detalhamento da Metodologia para Execução do Zoneamento Ecológico Econômico pelos Estados da Amazônia Legal. Brasilia. SAE-Secretaria de Assuntos Estratégicos/ MMA Ministério do Meio Ambiente. 1996. 
CARVALHO, P. G. S. As veredas e sua importância no município dos cerrados. DAPHNE - Revista do Herbário PAMG, Belo Horizonte, v. 15, n. 168, p. 54-56, 1991.

CONGALTON, R. G. A review of assessing the accuracy of classifications of remotely sensed data. Remote Sensing of Environment, v. 49 n. 12, p. 1671-1678, 1991.

CUNHA, E. R. da ;BACANI, V. M.; FACINCANI, E. M.; SAKAMOTO, A. Y. ; LUCHIARI, A. Remote sensing and gis applied to geomorphological mapping of the watershed stream Indaia, MS, Brazil. In: 8th IAG International Conference on Geomorphology, 2013, Proceedings... Paris-France, 2013.

CUNHA, E. R. BACANI, V. M.; AYACH, L. R. Geoprocessamento aplicado à análise da fragilidade ambiental. Revista da ANPEGE, Presidente Prudente, v. 09, p. 91-121, 2013.

CREPANI, E. MEDEIROS, J. S. DE. HERNANDEZ FILHO, P. FLORENZANO, T. G. DUARTE, V. BARBOSA, C. C. F. Sensoriamento remoto e geoprocessamento aplicados ao Zoneamento Ecológico-Econômico e ao ordenamento territorial. São José dos Campos: Instituto Nacional de Pesquisas Espaciais - INPE, 2001.

DIRETORIA DO SERVIÇO GEOGRÁFICO DO EXÉRCITO (1966) - Folha SF-21-X-A-III - Aquidauana, Escala 1:100.000.

EMBRAPA. Dados de chuvas. Disponível em: < http://www. cpao.embrapa.br/clima/clima.cpao/index.php?pg=chuvams\&cidade $=$ Aquidauana. Acesso em: 15 de fevereiro de 2014 .

EXELIS VISUAL INFORMATION SOLUTIONS. ENVI/ software ENVI 5.1. Bolder, Colorado, 1 Cd Rom. 2014.

FITZ, P. R. Cartografia Básica. São Paulo: Oficina de Textos, 2008.

FUSHIMI. M, NUNES. J, O. R. NAKAMURA. R, Y. TAKATA. L, T.O. Vulnerabilidade Ambiental e Aplicação de Técnicas de Contenção aos Processos Erosivos Lineares em Áreas Rurais do Município de Presidente Prudente - SP. Revista Brasileira de Geomorfologia, Presidente Prudente, v. 14, p. 343-356, 2013.

GUERRA, A. J. T. MARÇAL, M. S. Geomorfologia Ambiental. Rio de Janeiro: Bertrand do Brasil, 2006.
INCRA, Instituto Nacional de Colonização e Reforma Agrária. Disponível em < http://www.incra.gov.br/index.php/noticias-sala-de-imprensa/noticias/9946-incra-lanca-complexo-de-assentamentos-em-aquidauana> Acesso, 13, abril, 2013.

IBAMA, Instituto Brasileiro de Meio Ambiente e dos Recursos Naturais Renováveis. Roteiro Metodológico para Gestão da Área de Proteção Ambiental. Brasília: Edições IBAMA, 2001.

KAGEYAMA, P. Y. Estudo para implantação de matas de galeria na bacia hidrográfica do Passa Cinco visando a utilização para abastecimento público. Piracicaba: Universidade de São Paulo. Relatório de Pesquisa.1986.

LANDIS, J. R. KOCH, G. G. The measurement of observer agreement for categorical data. Biometrics, v.33, n.1, p. 159-174, 1977.

LANDSAT OLI 8: imagem de satélite. Virginia: USGS United States Geological Survey,2015. 1 fotografia área. Escala 1:100.000. Bandas 1, 2, 3, 4, 5, 6, 7 e 8.

LIMA, W. P. Função da mata ciliar. In: SIMPÓSIO SOBRE MATA CILIAR, Campinas. Anais... Campinas: Fundação Cargil, p.25-42, 1989.

LOPES, S. L. J. CESTARO, L.A. KELTING, F. M. S. Zoneamento Ambiental como Instrumento de Uso e Ocupação do Solo do Município de Aquiraz-CE. Boletim Goiano de Geografia. Goiânia, v. 32, n. 1, p. 93-104. 2012.

OLIVEIRA, P. T. S. RODRIGUES, D. B. B. ALVES SOBRINHO, T. E. PANACHUKI, Zoneamento Ambiental Aplicado à conservação do Solo e da Água. Revista Brasileira Ciência do Solo. Viçosa, v. 35, p. 1723-1734, 2011.

PEIXOTO, K, S. SANCHEZ. M. PEDRONI. F. RIBEIRO. M, N. KLEIN. V, L. G. GUILERME. F, A.G. Dinâmica da Comunidade Arbórea em uma Floresta Estacional Semidecidual sob Queimadas Recorrentes. Acta Botanica Brasilica. Belo Horizonte. v. 26, n 3. p. 697-708. 2012.

PINTO, A. L, Saneamento básico e suas implicações na qualidade das águas subterrâneas da cidade de Anastácio (MS). Tese (Doutorado em Geociências) Universidade Estadual Paulista/Instituto de Geociências e Ciências Exatas, 175p. Rio Claro,1998. 
PIRES, L. C. SILVA, L. F. MENDONÇA, B. G. BACANI, V. M. Análise da fragilidade ambiental do município de Aquidauana-MS. Revista Caderno de Geografia - PUC Minas. v.25, n.43, p. 52-65. 2015.

REMPEL, C. ECKHARDT, R. R. SHULTZ, G. PÉRICO, E. CYRNE, C. C. S. Zoneamento Ecológico-Econômico - ZEE - Para Sistemas Orgânicos de Produção Agropecuária. TECNO-LÓGICA, Santa Cruz do Sul. v. 16, n. 2, p. 90-97. 2012.

RIBEIRO. M, N. SANCHEZ. M. PEDRONI. F. PEIXOTO, K, S. Fogo e Dinâmica da Comunidade Lenhosa em Cerrado Sentido Restrito, Barra do Garças, Mato Grosso. Acta Botanica Brasilica. Belo Horizonte. v. 26, n 1. p. 203-217. 2012.

ROSS, J. L. S. Análise Empírica da Fragilidade dos Ambientes Naturais e Antropizados. Revista do departamento de geografia. São Paulo. n 8. 1994.

ROSS, J. L. S. Ecogeografia do Brasil. São Paulo: Oficina de Textos, 2006.

ROSS, J. L. S. Land forms and environmental planning: potentialities and fragilities. Revista do Departamento de geografia, São Paulo. Edição Especial, p. 38 - 51. 2012.

SANT"ANNA NETO, J. L. Algumas considerações sobre a dinâmica climática da porção sudeste do Pantanal Sul-mato-grossense. Boletim Paulista de Geografia. São Paulo n. 67. p.75-88. 1989.

SILVA, J. S. V. POTT, A. ABDON, M. M. POTT, V. J. SANTOS, K, R. Projeto GeoMS: Cobertura vegetal e uso da terra do Estado de Mato Grosso do Sul. Campinas: Embrapa Informática Agropecuária, p. 64. 2011.

SILVA NETO, J. C. A. Zoneamento Ambiental como Subsídio para o Ordenamento do Território da Bacia Hidrográfica do Rio Salobra, Serra Da Bodoquena - MS. RA'EGA Curitiba. v.32, p.119-142. 2014.

TRIMBLE GEOSPATIAL. Software eCognition Developer 8.0. Disponível em: < http://www.ecognition.com/ suite/ecognition-developer>. Acesso em: 16 abr. 2015.
THOMAS, B. L. Proposta de Zoneamento Ambiental para o Município de Arroio do Meio - RS. RA'E GA, Curitiba, v. 24. p. 199-226. 2012.

VALERIANO, M. de M. TOPODATA: guia de utilização de dados geomorfométricos locais - São José dos Campos: INPE, 2008.

\section{AGRADECIMENTO}

Os autores agradecem ao CNPq pelo apoio financeiro do projeto $n^{\circ}$ 400691/2011-6 e concessão de bolsas de iniciação científica e mestrado acadêmico.

\section{Correspondência dos autores:}

Leandro Félix da Siva e-mail: felixhc.le@hotmail.com

Elias Rodrigues da Cunha e-mail: eliasrodriguesdacunha@hotmail.com

Vitor Matheus Bacani e-mail: vitor.bacani@ufms.br

Artigo recebido em: 01/06/2017

Revisado pelos autores em: 03/11/2017

Aceito para publicação em: 20/01/2018 